\title{
JRCICE2007-40065
}

\section{ESTIMATION OF THE FATIGUE LIFE OF RAILROAD JOINT BARS}

\author{
Brandon Talamini \\ David Y. Jeong \\ David.Y.Jeong@volpe.dot.gov \\ US Department of Transportation \\ Jeff Gordon \\ Brandon.Talamini@volpe.dot.gov \\ Jeffrey.Gordon@volpe.dot.gov \\ Research and Innovative Technology Administration \\ John A. Volpe National Transportation Systems Center \\ Cambridge, MA 02142 USA
}

\section{ABSTRACT}

This paper investigates the influence of physical track conditions in the vicinity of a rail joint on the fatigue life of the joint bars. Recent derailments due to broken joint bars, such as the Minot, ND accident in January 2002, have highlighted the need for better understanding of the effects of joint conditions on premature joint bar failure. Fatigue life estimates can be used to guide the selection of inspection intervals for joint bars in service.

Engineering approximations are used to infer the dynamic load factor at a rail joint due to joint characteristics including:

- rail end gap

- joint efficiency (looseness)

- track stiffness (vertical foundation modulus)

A three-dimensional finite element analysis of a rail joint is conducted and the dynamic load is applied to develop an estimate of the live (bending) stresses at the joint due to passing wheels. These stresses are then used to estimate the fatigue life of the joint bars.

The methodology is demonstrated for 132RE rail with companion joint bars. The effect of thermal expansion (or the temperature difference below the rail neutral temperature) is investigated. Typical wheel loads and railcar speeds are considered and results are presented for a baseline a joint condition.

\section{INTRODUCTION}

Past rail integrity research has focused on defects that occur in continuous welded rail (CWR). For example, particular attention has been given to the formation and growth of an internal rail defect called a detail fracture $[1,2]$. Although research has been conducted to examine bolt-hole cracking $[3,4,5]$, the structural integrity of bolted rail joints has not been studied as thoroughly as that in CWR. The emphasis on defects in continuous welded rail stems, in large part, from the increasing trend in the railroad industry to replace bolted joint rail with CWR. Rail joints, however, cannot be completely eliminated. For example, bolted joints are sometimes used to connect strings of CWR. Bolted joints are frequently used for temporary repairs, and may also be used in sharp curves in which rapid wear may require frequent rail replacement. Insulated joints are used to isolate the electric current within certain sections of track, and as such can be used as a means to detect broken rails.

Jensen [6] examined fatigue life of joint bars experimentally using rolling-load tests and noted the important fact that bars failed more often at the head than at the base. Fatigue and fracture of railroad joint bars were examined in a recent study of certain aspects related to the structural integrity of bolted rail joints [7].

The structural integrity of bolted rail joints has come under scrutiny because joint failures have been involved in

This material is declared a work of the U.S. Government and is not subject to copyright protection in the United States. Approved for public release; distribution is unlimited. 
recent train derailments, which in turn have led to the accidental release of hazardous material:

- In March 1996, more than 3,000 people were evacuated in Weyauwega, Wisconsin when seven tank cars filled with liquid propane gas derailed and caught fire. The cause of the derailment is believed to have been a broken switch-point rail, which originated from an undetected bolt-hole crack.

- In May 2000, 33 of 113 cars derailed near Eunice, Louisiana. The derailment resulted in a release of hazardous materials with explosions and fires. About 3,500 people were evacuated from the surrounding area. An investigation conducted by the National Transportation Safety Board (NTSB) determined that the probable cause was the failure of a set of joint bars that had remained in service with undetected defects.

- In January 2002, 31 of 112 cars derailed near Minot, North Dakota. Several tank cars released over 200,000 gallons of anhydrous ammonia, which resulted in one fatality, over 300 injuries, and affected over 15,000 local residents. Broken joint bars and undetected defects were involved in this derailment.

The increased visibility of bolted joint fatigue failures calls for a methodical engineering analysis to guide the selection of inspection intervals. In this paper, a methodology for determining fatigue life estimates of bolted rail joints is developed and applied to a baseline rail joint scenario.

\section{DYNAMIC WHEEL LOAD ESTIMATION}

The calculation of vertical dynamic loads is based on a modification of a method originally developed by British Rail [9]. Referring to Figure 1, the vertical dynamic loads resulting from wheel/rail impact at a joint are assumed to consist of a short-time peak $\left(P_{1}\right.$ load $)$ and a delayed peak $\left(P_{2}\right.$ load). The short-time peak is associated with battering of the rail-end corner by the unsprung mass of the wheel set. The delayed peak is associated with rail bending, which is a more resilient deformation mode than corner batter. Consequently, $P_{1}$ is larger than $P_{2}$, and the difference between the short-time and delayed peaks increases as the train speed increases. Also, the duration of the delayed peak is about four to ten times the duration of the short-time peak. Moreover, $P_{1}$ is related to the inertias of the rail and ties, while $P_{2}$ is transmitted to the ballast, which produces track deflections. In this study, the effect of various track and operational parameters on the $P_{2}$ load is examined.

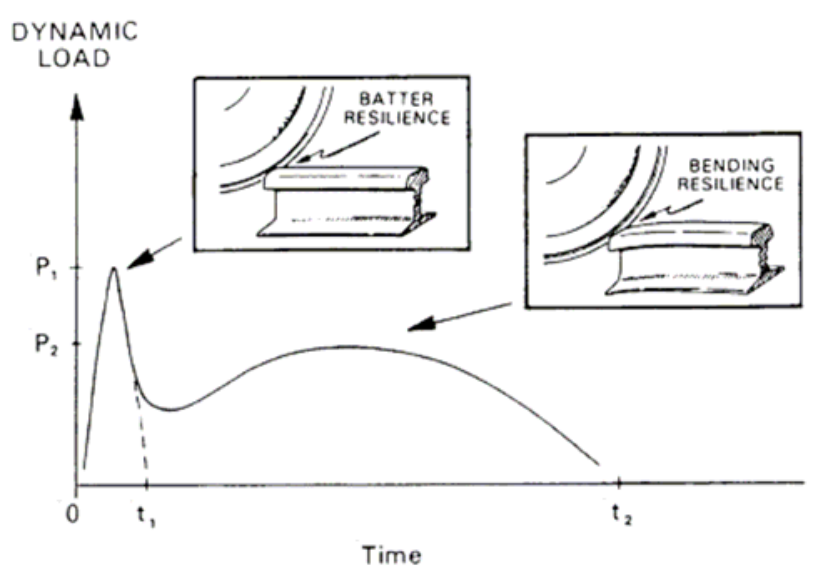

Figure 1: Variation of dynamic load due to wheel/rail contact at joint.

The AREMA Manual for Railway Engineering cites the following formula for dynamic load factor $(D L F)$ [8]:

$D L F=1+\frac{33 V_{m p h}}{100 D}$

where $V_{m p h}$ is the train velocity in miles per hour and $D$ is the wheel diameter in inches. The total wheel load is then calculated as the product of the dynamic load factor and the static wheel load, $P_{0}$ :

$P_{\text {TOT }}=P_{0}\left(1+\frac{33 V_{m p h}}{100 D}\right)$

where $P_{0}$ is the static wheel load and $R$ is the wheel radius in inches. These equations, however, apply to a continuous rail. That is, equations (1) and (2) apply to rails without joints.

The present study involves the calculation of dynamic loads at rail joints. The equations of motion for a wheel moving at constant speed along a track with a rail joint are derived and presented in [7]. The analysis assumes that the vector direction of the velocity changes suddenly when the wheel encounters the rail joint.

Referring to Figure 1, the delayed-peak or $P_{2}$ load is calculated from

$P_{2}=P_{0}+\frac{M_{u} V^{2}}{R}\left[\sqrt{1+\frac{K_{r} \alpha^{2} R^{2}}{M_{u} V^{2}}}-1\right]$

where $M_{u}$ is the unsprung mass of the wheelset, $K_{r}$ is the rail stiffness, $V$ is the train speed, $R$ is the wheel radius and $\alpha$ is the effective joint dip angle. The effective joint dip angle is considered to be comprised of four parts. The first contributor, $\alpha_{l}$, is related to dip angle that would occur in continuous rail (if the joint were not present). The remaining components of $\alpha\left(\alpha_{2}, \alpha_{3}, \alpha_{4}\right)$ are related to the physical conditions at the joint, namely rail end gap, rail bending and rail end batter (or height mismatch). The derivation of the

This material is declared a work of the U.S. Government and is not subject to copyright protection in the United States. Approved for public release; distribution is unlimited. 
components of the effective dip angle is described in Appendix A.

Given the following assumptions

$$
\begin{array}{ll}
M_{u} & 4.53 \mathrm{lb}-\mathrm{s}^{2} / \mathrm{in} \\
K_{r} & 3.3 \times 10^{5} \mathrm{lb} / \mathrm{in} \\
V & 704 \mathrm{in} / \mathrm{s}(40 \mathrm{mph}) \\
R & 18 \mathrm{in} \\
\alpha & 0.055 \text { radians assuming a rail end gap of } 1 / 8 \text { inch } \\
& \begin{array}{l}
\text { and no rail end batter or height mismatch (as } \\
\text { shown in Appendix A) }
\end{array}
\end{array}
$$

and a static load, $P_{0}=19,000 \mathrm{lb},{ }^{1}$ the dynamic load at the joint, $P_{2}$, from equation (3) is $27,739 \mathrm{lb}$ and the $D L F$ is $P_{2} / P_{0}$ or 1.46. When the wheel is not at the joint, the joint characteristics no longer contribute to the dynamic load, and the $D L F$ is equal to that obtained from the AREMA formula in equation (1). Assuming a wheel diameter $D$ of 36 in, the $D L F$ is 1.367 and the dynamic load $P_{T O T}$ is $25,973 \mathrm{lb}$ from equation (2).

\section{ENGINEERING ESTIMATES OF STRESSES IN JOINT BARS}

For this study, 132RE rail and its companion 36-inch joint bars, shown in Figure 2, have been chosen to illustrate the method.

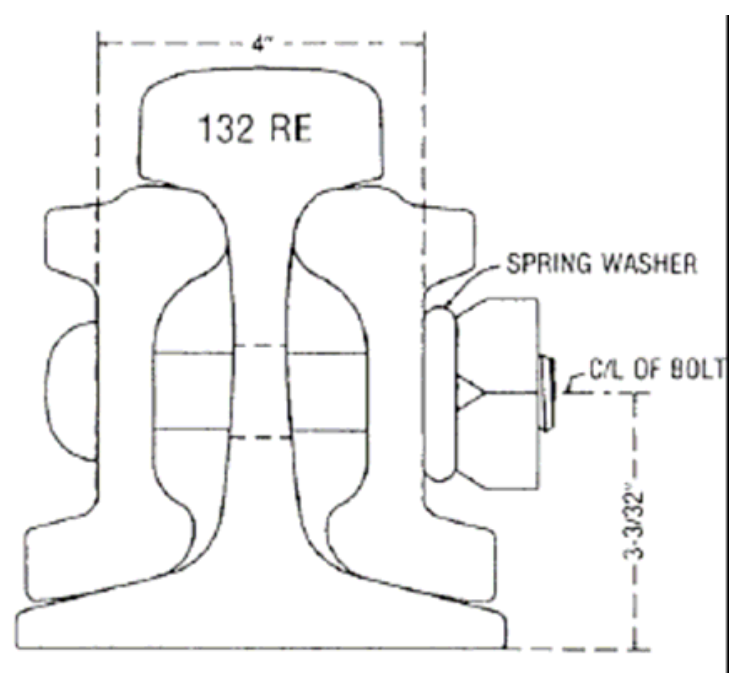

Figure 2: 132RE rail and joint bar assembly [8].

The longitudinal bending moment distribution in a continuous rail is calculated from the equations for an infinite beam on elastic foundation, and is equal to

\footnotetext{
1 The static load, $P_{0}$, was chosen based on AAR InteRRIS data and represents the average wheel load from 150 trains traveling over 12 wheel impact load detector (WILD) sites sampled three times in a 12-month period.
}

$M_{R}(x)=\frac{P}{4 \lambda}[\exp (-\lambda x)(\cos \lambda x-\sin \lambda x)]$

where $P$ is the dynamic wheel load from equation (3), $P_{2}$, and

$\lambda=\sqrt[4]{\frac{k_{v}}{4 E I_{R}}}$

in which $k_{v}$ is the rail foundation modulus $(3,000 \mathrm{lb} / \mathrm{in} / \mathrm{in}$ is assumed here), $E$ is the modulus of elasticity $\left(30 \times 10^{6} \mathrm{psi}\right.$ is assumed for rail steel), and $I_{R}$ is the rail bending inertia ( 88.2 $\left.i^{4}\right)$. The bending moment is maximum at the point of application of the load $(x=0)$ where

$$
M_{R}(0)=\frac{P_{2}}{4 \lambda} .
$$

Joint bars are also assumed to behave as beams in bending and are assumed to carry only a fraction of the moment in a continuous rail. This fraction is called the joint efficiency factor, $\beta$. Laboratory and field tests indicate that the joint efficiency factor depends on the condition of the joint (i.e., looseness of the joint ${ }^{2}$ ), but for a good joint it varies between 0.6 and 0.8 [9]. The theoretical maximum joint efficiency factor is

$$
\beta_{\max }=\left(\frac{M_{J}}{M_{0}}\right)_{\max }=\sqrt[4]{\frac{I_{J}}{I_{R}}}
$$

where $I_{J}$ and $I_{R}$ are the vertical bending inertias for the joint bars and rail respectively.

The bending moment carried by the joint bars $\left(M_{J}\right)$ is assumed to be

$$
M_{J}=\beta M_{0}=\beta \frac{P_{2}}{4 \lambda} .
$$

The maximum bending stress at the top of the joint bar is compressive when the wheel is located at the joint and is equal to

$$
S_{J-}=\frac{M_{J} c_{J}}{I_{J}}
$$

where $c_{J}$ is the distance from the joint bar neutral axis to the top of the joint bar (2.42 in) as shown in Figure 3 and $I_{J}$ is the moment of inertia of the joint bar pair $\left(32.38 \mathrm{in}^{4}\right)$.

This material is declared a work of the U.S. Government and is not subject to copyright protection in the United States. Approved for public release; distribution is unlimited. 


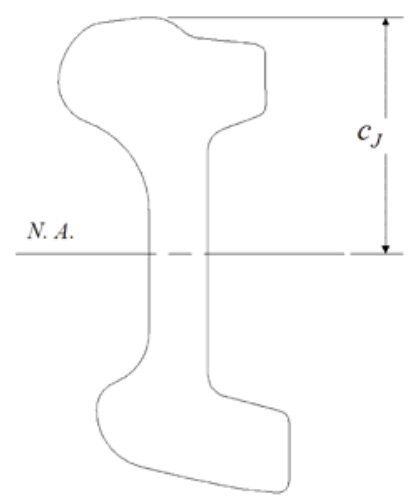

Figure 3: Depth to neutral axis of joint bar, $c_{J}$.

As the wheel moves away from the joint location, the moment distribution evolves and the rail is subjected to reverse bending. The maximum reverse bending stress at the top of the joint bar is tensile and occurs when the wheel is a distance $x_{r b}$ from the joint, which is determined by differentiating equation (4). The moment at this location is determined by applying equation (4) with $P=P_{\text {TOT }}$. The stress in the joint bar is related to the moment at this location and is equal to

$S_{J+}=\frac{\beta M_{R}\left(x_{r b}\right) c_{J}}{I_{J}}$.

Each wheel pass is assumed to create a single stress cycle. For the purposes of estimating fatigue life, the $S_{J-}$ and $S_{J+}$ stresses represent one loading cycle. Each wheel in this analysis is assumed to have the same static load and cause the same amount of fatigue damage with each pass.

The fatigue life of joint bars is adversely affected by stresses imposed by rail thermal contraction when the ambient temperature is below the rail neutral temperature. The thermal load in rail, $P_{t h}$, is equal to

$P_{t h}=A_{R} E \alpha_{t h} \Delta T$

where $A_{R}$ is the rail cross-sectional area $\left(12.95 \mathrm{in}^{2}\right.$ for 132RE rail) $\left(83.55 \mathrm{~cm}^{2}\right), \alpha_{t h}$ is coefficient of thermal expansion (for rail steel, $6.5 \times 10^{-6} /{ }^{\circ} \mathrm{F}$ is assumed $)\left(117 \times 10^{-3} /{ }^{\circ} \mathrm{C}\right)$ and $\Delta T$ is the temperature difference below neutral $\left({ }^{\circ} \mathrm{F}\right)$. Thermal loads are imparted to the joint bars when the rail longitudinal displacement exceeds the gap distance between the joint bolts and the drilled holes in the rail end. For a 1 in bolt in a $1 \frac{1}{8}$ in hole, a temperature differential $\Delta T$ of approximately $10^{\circ} \mathrm{F}$ is required to cause the joint bolts to begin to carry thermal load, assuming that the rail longitudinal resistance is $15 \mathrm{lb} / \mathrm{in}$ (a typical value for an every-other-tie anchoring pattern). For greater $\Delta T$ the thermal load imparts a tensile stress, $S_{t h}$, in the joint bar

$S_{t h}=\frac{P_{t h}}{A_{J}}$ where $A_{J}$ is the joint bar cross-sectional area $\left(11.78 \mathrm{in}^{2}\right.$ for 132RE joint bars). For the baseline fatigue life estimate, $\Delta T$ is assumed to be $20^{\circ} \mathrm{F}$.

\section{FINITE ELEMENT ESTIMATES OF STRESSES IN JOINT BARS}

Two finite element models are used to estimate the magnitude of the live stresses used in the fatigue calculations. One model is used to calculate stresses when the wheel is directly over the joint; the other model is used to calculate the reverse bending stresses when the wheel is at a distance $x_{r b}$, from the joint, as defined previously. Separate models are utilized to take advantage of the symmetries of both loading scenarios. The wheel-over-joint loading condition possesses longitudinal symmetry across the vertical plane in the center of the rail gap; no such longitudinal symmetry exists for the reverse bending condition (see Figure 4). Hence, separate models are used for each condition with the appropriate symmetry constraints (see Figures 5 and 6 ). Lateral symmetry is assumed for both loading conditions; lateral wheel loads are not treated in this paper. The reverse bending model geometry is identical to the wheel-over-joint model plus its mirror image reflected across the rail gap. All other attributes are shared. Therefore, the features of the models are discussed together. Both models are depicted in Figures 5 and 6. The wheel-overjoint model contains approximately 37,000 first-order, hexahedral elements and 57,000 nodes. The commercial code ABAQUS is used for analysis [10].

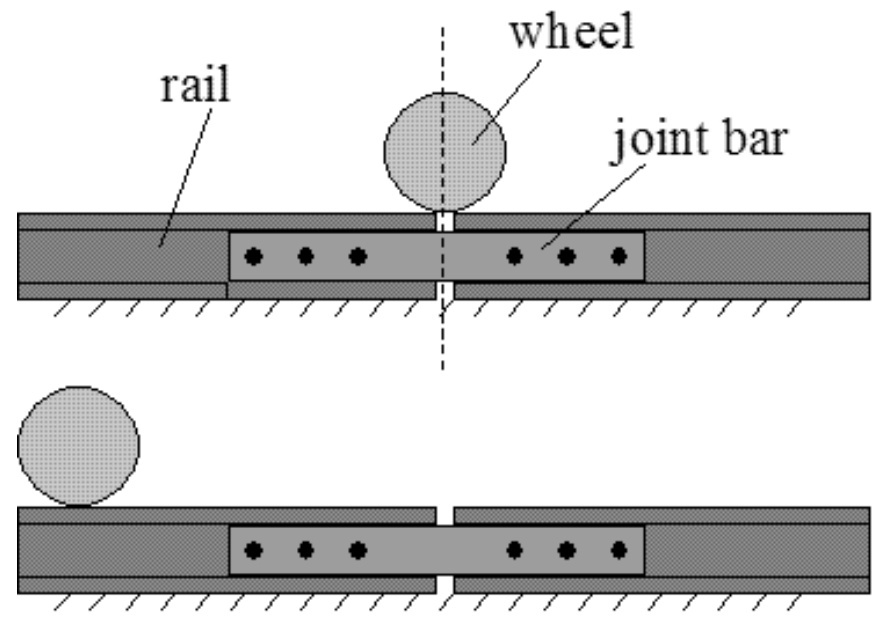

Figure 4 Top: Loading condition of wheel at joint possesses longitudinal symmetry. Bottom: No longitudinal symmetry exists for the reverse bending condition (Not to scale).

This material is declared a work of the U.S. Government and is not subject to copyright protection in the United States. Approved for public release; distribution is unlimited. 


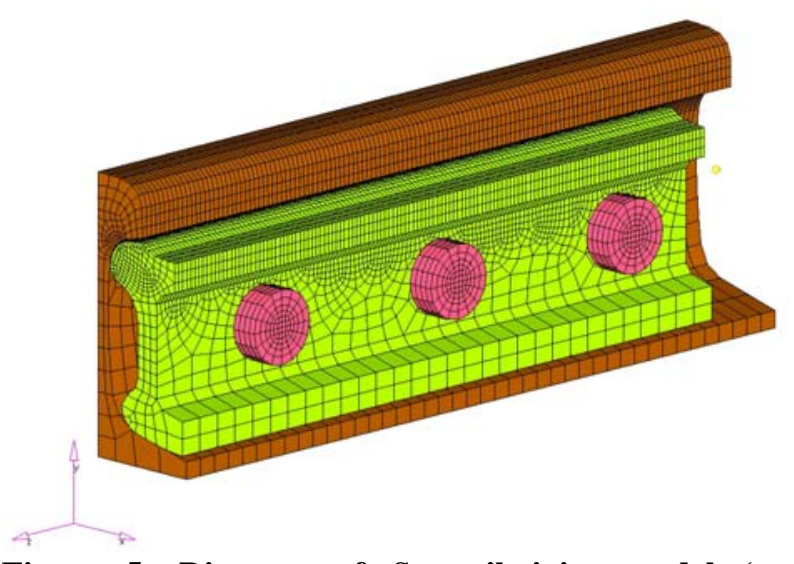

Figure 5: Diagram of $S_{J-}$ rail joint model (quartersymmetry).

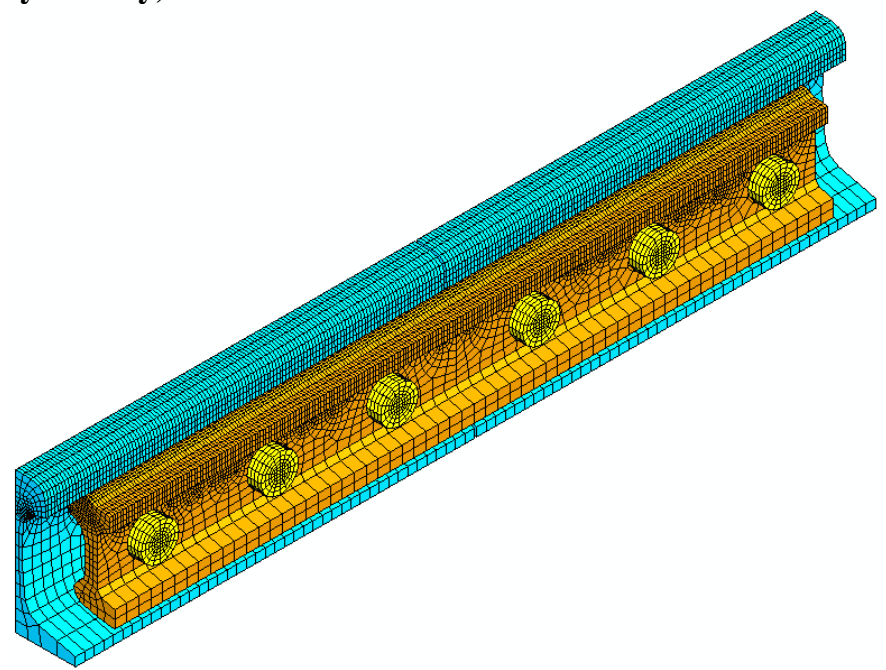

Figure 6: Diagram of $S_{J_{+}}$rail joint model (half-symmetry)

Salient features of the models are shown in Figures 7 through 11. Referring to Figure 7, the following features are labeled: lateral symmetry is enforced at the joint bar center plane $A$ in the wheel-over-joint model through boundary conditions. The distance between the end of the rail and the symmetry plane of the joint bar is one-half the rail joint gap (shown more clearly in Figure 8). In the case studied here, the rail joint gap, $g$ is $1 / 8$ in. Springs are located at point $B$ between the rail and ground to represent the vertical and longitudinal foundation stiffness. These springs are centered across the joint with a 20 in spacing. The spring constant for 20 in tie pitch and a 3,000 $\mathrm{lb} / \mathrm{in} /$ in foundation modulus is $60,000 \mathrm{lb} /$ in. At location $C$, constraint equations are applied to the nodes on this face to couple these elements to beam elements. The beam elements extend from $C$ approximately 200 in to model the rest of the rail in a computationally efficient manner. A multi-point constraint ${ }^{3}$ is defined so that the nodes on the face of the rail at $C$ remain planar during loading [10]. The rotation and vertical displacement of this face are coupled to a reference node. The beam elements connect to this reference node and extend to the right approximately 200 in, with springs modeling the ties and foundation spaced at 20 in intervals (see Figure 9).
A.

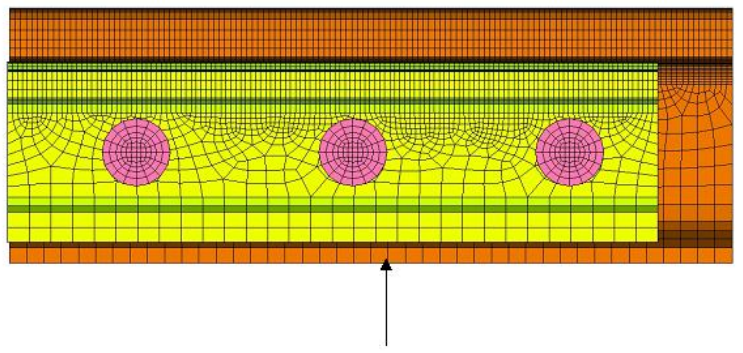

B.
Figure 7: Lateral view of model with salient features labeled. $A$. The center cross-section of the joint bar. $B$. Location of the foundation springs. $C$. Multi-point constraint connecting solid elements to beam elements.

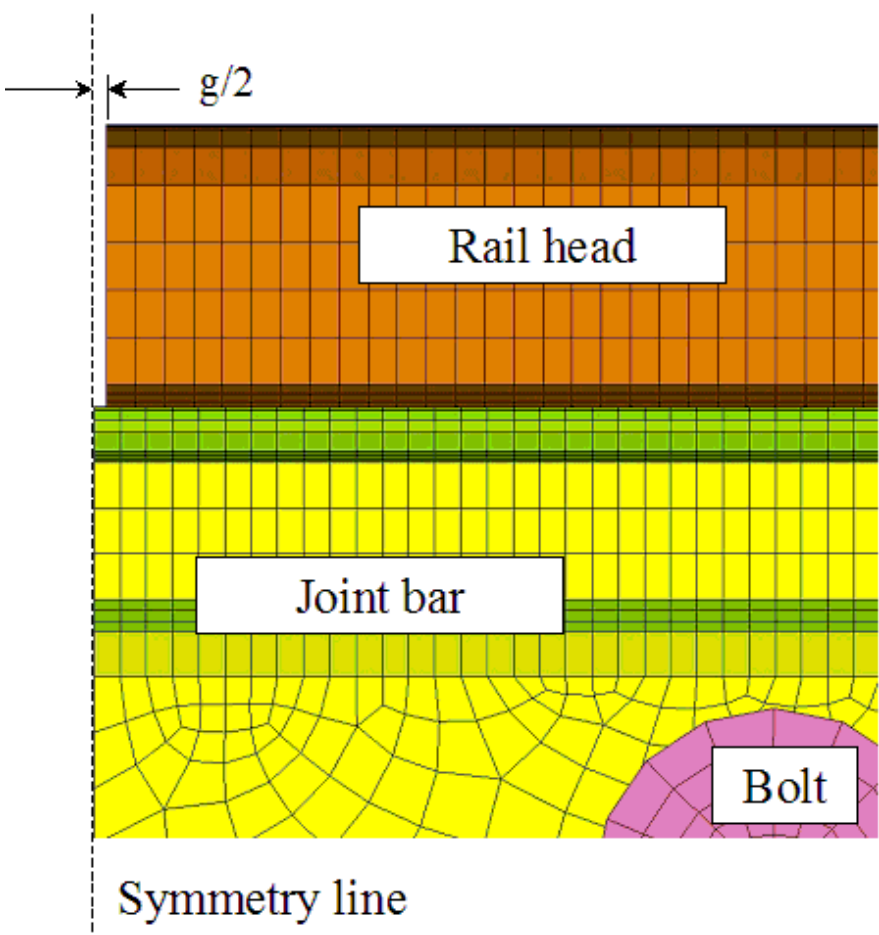

Figure 8: Close-up view of $A$. The half rail gap distance g/2 is shown.

\footnotetext{
${ }^{3}$ The constraints are enforced in ABAQUS through the *COUPLING and *DISTRIBUTING options.
}

This material is declared a work of the U.S. Government and is not subject to copyright protection in the United States. Approved for public release; distribution is unlimited. 


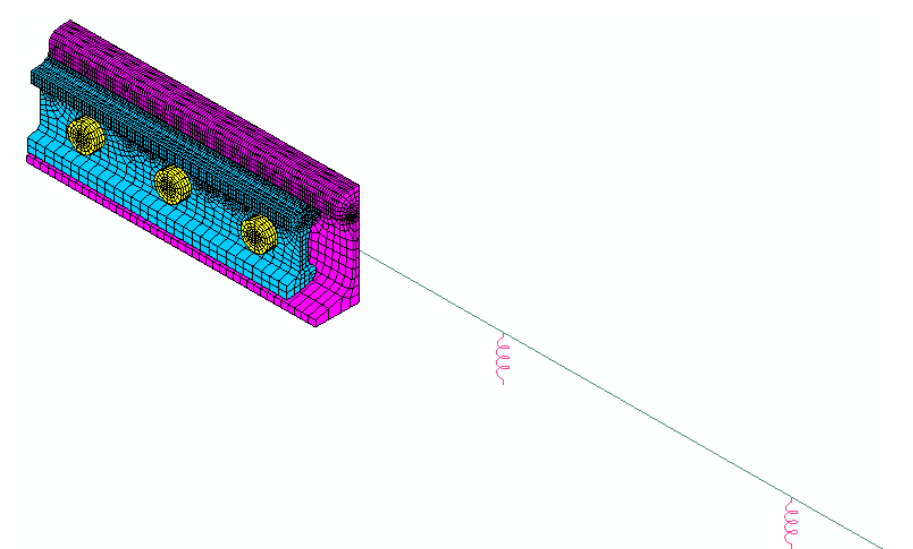

Figure 9: Connection of beam elements to solid elements. Beam elements representing rail and spring elements representing foundation continue beyond the edge of the picture.

Contact capabilities within ABAQUS are used to define interactions between the bolts and the joint bar, between the joint bar and the rail, and between the bolts and the rail. Initially, weak springs are attached to the joint bar to remove rigid body displacement modes. An initial step is used to tighten the bolts, clamping the joint bar to the rail. This is accomplished with the prescribed assembly load capability in ABAQUS [10] $]^{4}$. The baseline bolt tension is 7,500 $\mathrm{lb}$. Once contact is established between the joint bar and rail by the bolts, the springs are removed from the joint bar. At this point, the analysis proceeds to the loading steps.

Part of the joint bar manufacturing process is to create an easement, or depression, centered longitudinally in the head of the joint bar (under the rail gap, see Figure 10). This easement is intended to relieve knife-edge contact between the ends of the rail and the top of the joint bar by introducing some clearance between them. AREMA requires an easement of at least 3/64 in for rail sections over $119 \mathrm{lb} / \mathrm{yd}$ [8]. The implementation of the easement in the models is shown in cross-section at the center of the bar in Figure 11.

Friction is defined between the bolt head bearing surface and the joint bar surface. A coefficient of friction of 0.2 is assumed. If the static friction is overcome, the joint bar and rail may displace longitudinally with respect to one another until the bolt shanks contact the bolt hole surfaces of the rail and bar.

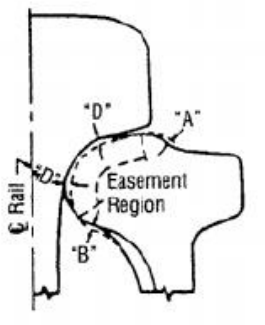

PART SECTION

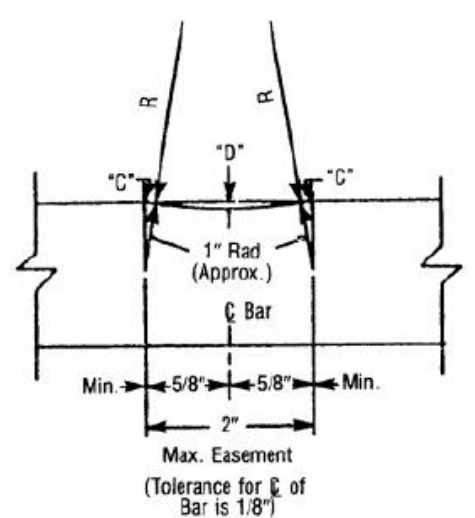

PART ELEVATION

Figure 10: Recommended head easement for joint bars [8].
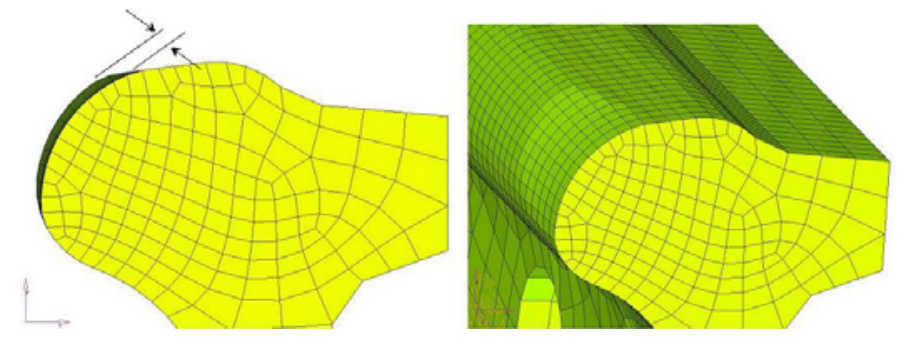

Figure 11: Close-up view of the easement at the center cross-section of the joint bar in the finite element models.

In the wheel-over-joint model, the wheel is represented by a rigid cylindrical surface (see Figure 12). Loads are applied through the rigid surface to the rail through a contact interaction. The load is derived from Equation (3).

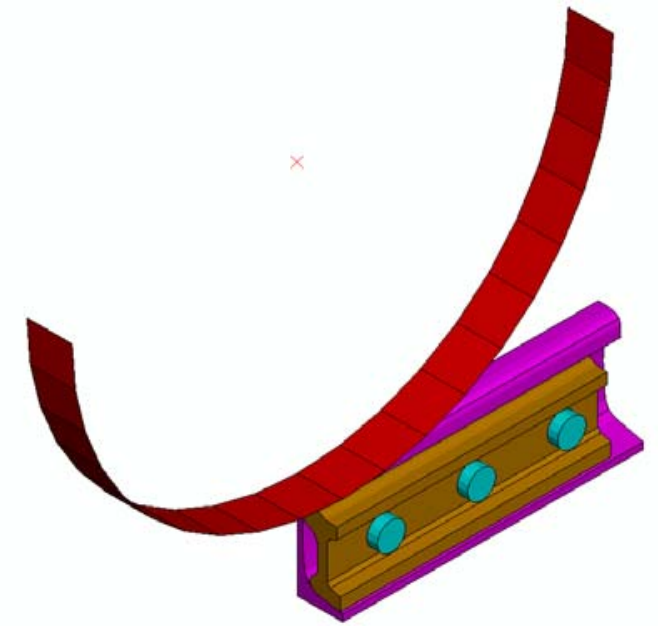

Figure 12: Finite element model, including rigid wheel surface.

In the reverse bending model, the wheel force is applied at a concentrated load at a node located a distance $x_{r b}$ from the

${ }^{4}$ The *PRE-TENSION SECTION option is employed for this effect.
After the initial tightening step, the bolt tension is allowed to vary based on the response of the structure.

This material is declared a work of the U.S. Government and is not subject to copyright protection in the United States. Approved for public release; distribution is unlimited. 
joint. This node, illustrated in Figure 13, is part of the beam element portion of the model. The reverse bending load is calculated from Equation (2).

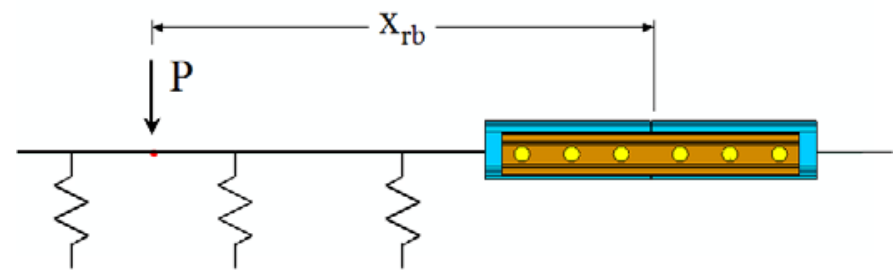

Figure 13: Schematic of reverse bending load application point in finite element model.

Results are extracted for the bending stresses $S_{J-}$ and $S_{J+}$ for use in the fatigue life estimates. Figures 14 and 16 show the contours of the axial stressing the joint bars under both loading conditions. In both figures, the near end of the bar in the illustration is the cross-section of the joint bar at the center of the rail gap. The reverse bending case, Figure 14, shows axial stress varying linearly. This indicates that the joint bar is experiencing nearly pure bending about its major axis. The bolted joint behaves similarly to beam on elastic foundation when the load is applied away from the joint. This is shown in the displaced geometry plot in Figure 15. The load is applied at the point of maximum deflection. The figure shows that the joint, on the right, is deforming similarly to the rail beam elements on the left, and thus is behaving in a beam-like manner.

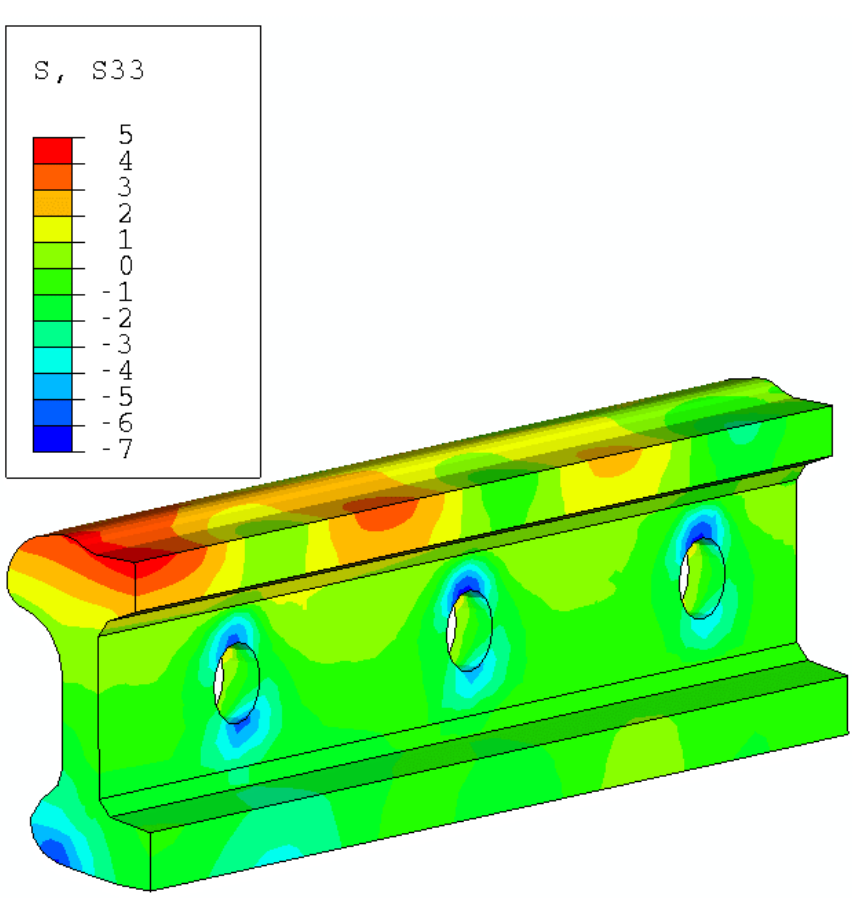

Figure 14: Contours of bending stress $S_{J^{+}}$at baseline conditions. Bar is shown sectioned at the longitudinal symmetry plane.

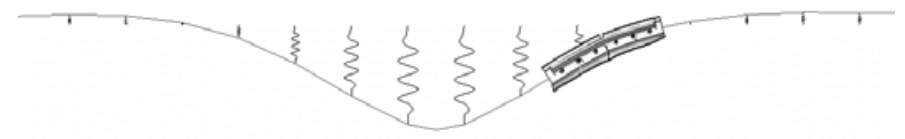

Figure 15: Portion of reverse bend model near load application point (deflection scaled by factor of 400 ).

Contours of the axial stress for the wheel-over-joint condition are shown in Figure 16. These contours show a diagonal pattern indicative of two-axis bending. In this condition, the load is applied very near to the examined section of the joint bar. The pressure imparted by the underside of the rail head to the joint bar has a vertical and lateral component, due to the curved geometry. These components induce bending in the joint bar about both its major and minor principal axes. This behavior is not accounted for in the engineering estimate model.

This material is declared a work of the U.S. Government and is not subject to copyright protection in the United States. Approved for public release; distribution is unlimited. 


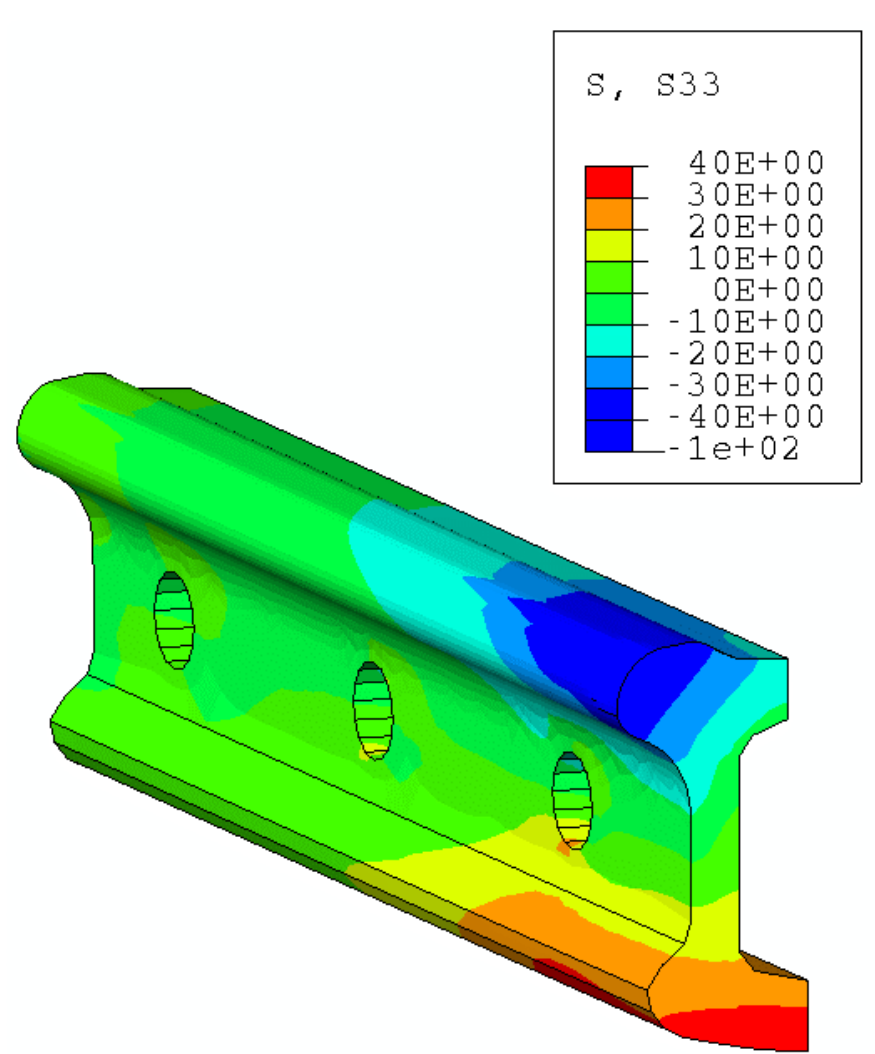

Figure 16: Contours of bending stress $S_{J-}$ at baseline conditions. Bar is shown sectioned at the longitudinal symmetry plane.

\section{FATIGUE LIFE ESTIMATES}

The rail fatigue properties used in the present calculations were derived from experiments conducted by Jensen [11]. Comparisons with other rail fatigue data suggest that the Jensen data represent rail properties associated with fatigue lives in the first-percentile range. ${ }^{5}$

The calculations for the fatigue life of joint bars are carried out using Miner's Law expressed as

$N=N_{0}\left[\frac{S_{0}\left(S_{U}-S_{M}\right)}{S_{U} S_{A}}\right]^{1 / k}$

in which $N$ is the fatigue life in cycles, $N_{0}$ represents infinite life (in cycles), $S_{0}$ is the endurance limit, $S_{U}$ is the ultimate strength, and $S_{M}$ and $S_{A}$ are the mean stress and alternating stress, respectively. The Jensen fatigue properties for rail steel are incorporated into this equation by assuming the following values: $N_{0}=10^{7}$ cycles, $S_{0}=32,000 \mathrm{lb} / \mathrm{in}^{2}, S_{U}=130,000$ $\mathrm{lb} / \mathrm{in}^{2}$, and $k=0.14$. The mean and alternating stresses in Equation (13) are calculated from

\footnotetext{
5 First-percentile life means the time at which one percent of a large population of rails can be expected to have formed a sharp, visible crack.
}

$$
\begin{aligned}
& S_{M}=\frac{1}{2}\left(S_{\text {max }}+S_{\text {min }}\right) \\
& S_{A}=S_{\text {max }}-S_{\text {min }}
\end{aligned}
$$

where $S_{\max }$ and $S_{\min }$ are the maximum and minimum stresses in a given load cycle $\left(S_{J_{+}}\right.$and $\left.S_{J_{-}}\right)$. The fatigue life (in cycles) can be expressed in terms of million gross tons (MGT) of traffic by

$$
M G T=\frac{N P_{0}}{2000 * 10^{6}} .
$$

For the baseline conditions described above, the fatigue life of the joint bar is estimated to be nearly 1,700 MGT based on the engineering analysis and 41 MGT based on the finite element results. The engineering analysis estimates a relatively long life for a nominally "good" joint under average freight train loads and modest temperature differential below the rail neutral temperature. The finite element estimate for fatigue life is impacted negatively by the increased stress due to the effects of the two-axis bending.

Table 1: Fatigue life estimates

\begin{tabular}{|l|r|r|r|}
\hline & EQN & $\begin{array}{c}\text { ENGINEERING } \\
\text { ANALYSIS }\end{array}$ & $\begin{array}{c}\text { FINITE } \\
\text { ELEMENT } \\
\text { ANALYIS }\end{array}$ \\
\hline$S_{J-}$ & 9 & $-17,484 \mathrm{lb} / \mathrm{in}^{2}$ & $-35,000 \mathrm{lb} / \mathrm{in}^{2}$ \\
\hline$S_{J+}$ & 10 & $4,300 \mathrm{lb} / \mathrm{in}^{2}$ & $4,000 \mathrm{lb} / \mathrm{in}^{2}$ \\
\hline$S_{t h}$ & 12 & $4,287 \mathrm{lb} / \mathrm{in}^{2}$ & $\mathrm{~N} / \mathrm{a}$ \\
\hline$S_{\min }=S_{J^{+}}+S_{t h}$ & & $-13,197 \mathrm{lb} / \mathrm{in}^{2}$ & $-30,713 \mathrm{lb} / \mathrm{in}^{2}$ \\
\hline$S_{\max }=S_{J+}+S_{t h}$ & & $8,587 \mathrm{lb} / \mathrm{in}^{2}$ & $8,287 \mathrm{lb} / \mathrm{in}^{2}$ \\
\hline$S_{M}$ & 14 & $-2,305 \mathrm{lb} / \mathrm{in}^{2}$ & $-11,213 \mathrm{lb} / \mathrm{in}^{2}$ \\
\hline$S_{A}$ & 15 & $21,784 \mathrm{lb} / \mathrm{in}^{2}$ & $39,000 \mathrm{lb} / \mathrm{in}^{2}$ \\
\hline$N\left(10^{8}\right.$ cycles $)$ & 13 & 1.77 & 0.044 \\
\hline$M G T$ & 16 & 1,679 & 41 \\
\hline \multicolumn{2}{r|}{} & &
\end{tabular}

\section{CONCLUDING REMARKS}

The prescribed method in this paper may be used to estimate the fatigue life of bolted rail joints in a variety of conditions in addition to those investigated in this paper. The finite element model for reverse bending calculates joint bar bending stresses that are comparable to the engineering estimates based on beam on elastic foundation theory. The engineering estimates are, therefore, an efficient method to estimate the tensile reverse bending stress at the top outer fiber of the joint bar, which is important for fatigue crack growth calculations. However, the finite element model for the wheel over the joint calculates stresses that are higher than the engineering approach. These results suggest that the engineering approach provides reasonable estimates for vertical bending only. Moreover, the finite element analysis captures the combined effect of vertical and lateral bending; i.e., two-axis bending; which is not included in the beam theory approximations.

This material is declared a work of the U.S. Government and is not subject to copyright protection in the United States. Approved for public release; distribution is unlimited. 


\section{FUTURE WORK}

The fatigue calculations in this paper assume that the bar and rail are stress-free in the unloaded state. However, both of these components contain residual stresses from manufacturing. Incorporating these stresses into the present analysis remains to be examined. A finite element analysis process for determining the residual stresses in rails has been investigated [12]; this method will also apply to the similarly manufactured joint bars.

Additionally, geometric factors affecting the service life of bolted joints are not constant. Rail end batter, bolt loosening, rail height differential, joint camber, and out-to-out distances of joint bars may evolve over the service life of the joint components. A thorough study of these factors will be examined with the finite element models to give a more complete understanding of bolted joint fatigue.

\section{ACKNOWLEDGMENTS}

The work reported in this paper was carried out under the Rail Integrity program sponsored by the Office of Research and Development, Federal Railroad Administration, U.S. Department of Transportation, under the direction of Dr. Magdy El-Sibaie, Chief, Track Research Division. Mr. Ali Tajaddini is the Project Manager for the research related to rail integrity.

\section{REFERENCES}

[1] O. Orringer, Y.H. Tang, J.E. Gordon, D.Y. Jeong, J.M. Morris, and A.B. Perlman, "Crack Propagation Life of Detail Fractures in Rails," US DOT/RITA Volpe Center, Cambridge, MA, DOT/FRA/ORD-88/13 (October 1988).

[2] D.Y. Jeong, Y.H. Tang, and O. Orringer, "Damage tolerance analysis of detail fractures in rail," Theoretical and Applied Fracture Mechanics 28, 109-115 (1997).

[3] R.A. Mayville and P.D. Hilton, "Fracture mechanics analysis of a rail-end bolt hole crack," Theoretical and Applied Fracture Mechanics 1, 51-60 (1984).

[4] R.A. Mayville, P.D. Hilton, and D.C. Pierce, "Investigation of Rail Bolt Hole Cracks," Final Report, DTRS-57-83-C-0078 (October 1987).

[5] R.A. Mayville and R.G. Stringfellow, "Numerical analysis of a railroad bolt hole fracture problem," Theoretical and Applied Fracture Mechanics 24, 1-12 (1995).

[6] R.S. Jensen, "Twelfth Progress Report of the RollingLoad Tests of Joint Bars," Proceedings of the $53^{\text {rd }}$ Annual Convention of the American Railway Engineering Association, Vol. 55, 814-828 (1954).

[7] D.Y. Jeong, "Engineering Analysis of the Impact Load at Rail Joints and Its Effect on Fatigue and Fracture of
Joint Bars," US DOT/RITA Volpe Center, Cambridge, MA, DOT/FRA/ORD-04/06 (February 2004).

[8] Anon., AREMA Manual for Railway Engineering, Vol. 1, Track, American Railway Engineering and Maintenanceof-Way Association, (1999).

[9] H.H. Jenkins, J.E. Stephenson, G.A. Clayton, G.W. Morland, and D. Lyon, "The effect of track and vehicle parameters on wheel/rail vertical dynamic forces," Railway Engineering Journal 3, 2-26 (1974).

[10] ABAQUS/Standard User's Manual (version 6.6). ABAQUS, Inc., Providence, RI

[11] R.S. Jensen, "Fatigue tests of rail webs," American Railway Engineering Association Bulletin 51, 640-647 (1950).

[12] B. Talamini, J. Gordon, and A.B. Perlman, "Finite Element Estimation of the Residual Stresses in Roller Straightened Rail," Proceedings of the 2004 ASME International Mechanical Engineering Congress (2004).

[13] M. Hetenyi, Beams on Elastic Foundation, University of Michigan Press, Ann Arbor, MI (1983).

\section{APPENDIX A}

The effective joint dip angle is assumed to consist of four parts. The first part is considered as the minimum value of $\alpha$ which applies to a continuous rail and correlates with the AREMA formula. In other words, Equation (2) is equivalent to Equation (3) if

$$
\alpha_{1}=\frac{1}{320 R} \sqrt{\frac{3 P_{0}\left(3 P_{0}+640 M_{u} V\right)}{M_{u} K_{r}}}
$$

The three remaining components of $\alpha$ apply to the jointed rail. Specifically, the wheel is assumed to travel over a step change in vertical position as it passes over the joint. Figure A-1 shows a schematic of two sources for the change in vertical position. In the first case, the wheel drops a vertical distance $\delta_{0}$ into the gap between rail ends. The figure also shows a schematic of the other source for the change in vertical position; namely, rail bending.

This material is declared a work of the U.S. Government and is not subject to copyright protection in the United States. Approved for public release; distribution is unlimited. 

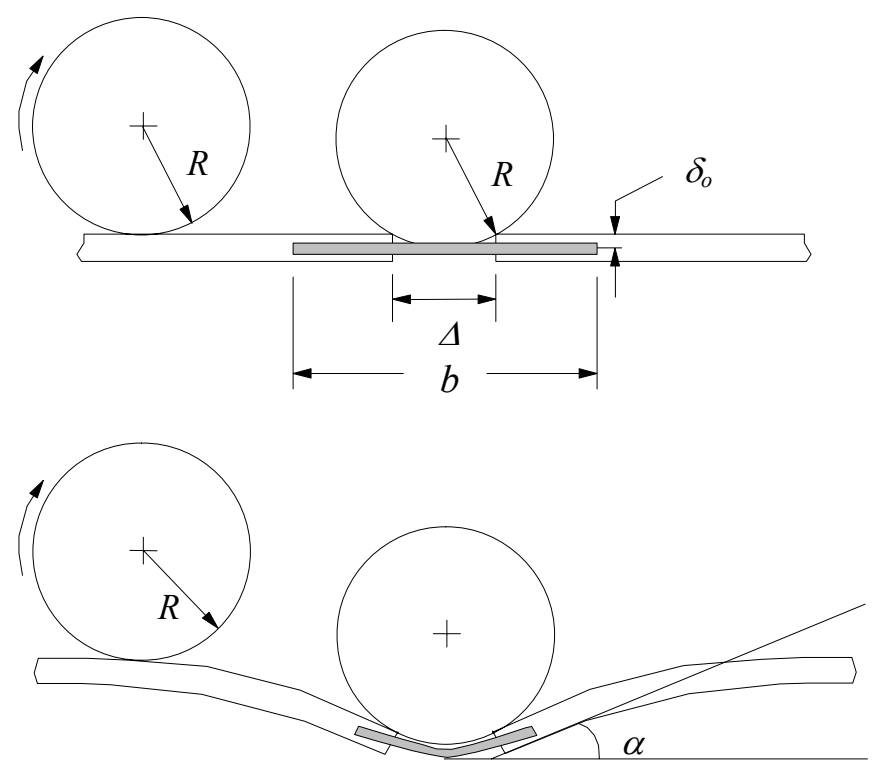

Figure A-1: Change in vertical position of wheel as it passes over a rail joint.

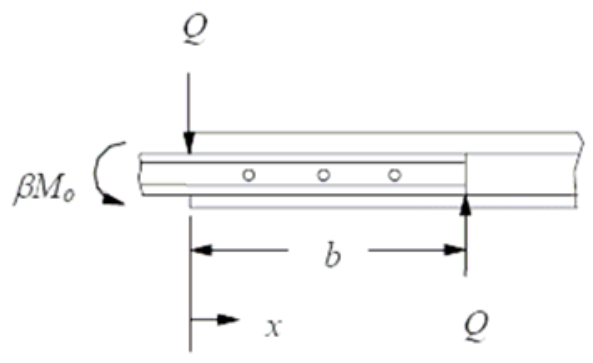

Figure A-2: Bolted joint moment free-body diagram.

The dip angle from the wheel dropping into the gap between rail ends is

$\alpha_{2}=\frac{\Delta}{2 R}$

where $\Delta$ is the gap distance or distance between rail ends at the joint.

Joint bars are assumed to behave as beams in bending. Referring to Figure A-2, the joint bar reaction is related to the bending moment by

$\beta M_{0}=Q b$

where $\beta$ is the joint efficiency factor and $M_{0}$ is obtained from Equation (7). Thus, the joint bar reaction load is a function of the joint efficiency factor, and is calculated from

$Q=\beta \frac{P}{4 \lambda b}$
The joint bar reactions are translated into forces that act on the rail, as shown in Figure A-3. The rails in the joint are assumed to behave as semi-infinite beams on elastic foundation. When the wheel is located at the center of the joint (i.e., at $x=0$ ), one-half of the wheel load is applied to each rail end in the joint. The principle of superposition is then used for the three loads $(P / 2$ and $-Q$ applied at the rail end, and $Q$ applied at a distance $b$ from the end) to calculate depressions, slopes, and moments of the rail.

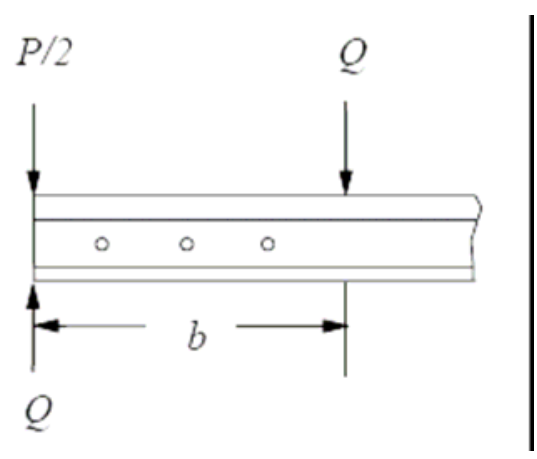

Figure A-3: Bolted joint shear free-body diagram.

The dip angle from bending of the rail end at the joint is calculated from semi-infinite beam on elastic foundation theory [13]:

$\alpha_{3}=2\left|\theta_{R J}(0)\right|=2\left\{\frac{P \lambda^{2}}{k_{v}}-\frac{2 Q \lambda^{2}}{k_{v}}\left[1-e^{-\lambda \ell}(\cos \lambda \ell-\sin \lambda \ell)\right]\right\}$

where $P$ is the applied wheel load, $Q$ is the joint-bar reaction load. Also,

$\ell=b-\frac{\Delta}{2}$

where $b$ is the half-length of the joint bar (18 inches). Because this component of the dip angle depends on the applied wheel load, the $P_{2}$ load is calculated in an iterative manner.

The fourth component of $\alpha$ accounts for another potential source for the change in vertical position of the wheel; namely, deformation of the rail ends due to batter. In this analysis, rail-end batter is characterized by its depth and length. The angle to account for this effect is

$\alpha_{4}=\frac{\delta}{L}$

Thus, the effective dip angle is the sum of the four components described above

$\alpha=\alpha_{1}+\alpha_{2}+\alpha_{3}+\alpha_{4}$

This material is declared a work of the U.S. Government and is not subject to copyright protection in the United States. Approved for public release; distribution is unlimited. 